\title{
Knowledge about HIV transmission, behavior and self- perception about risk of getting HIV among men
}

\author{
Oli N. L., Onta S. R. , Dhakal S. \\ Department of Community Medicine, Kathmandu medical College, Affiliated to Kathmandu University, Kathmandu \\ (Nepal); Department of Community Medicine and Family Health Maharajgunj Medical Campus, Institute of Medicine, \\ Tribhuvan University, Kathmandu (Nepal); Blue Diamond Society
}

Correspondence to: Dr. Natalia L Oli, Community Medicine Department, Kathmandu Medical College, Sinamangal, Kathmandu, Nepal

E-mail: olinatalia@hotmail.com

\begin{abstract}
Introduction: In spite on a lot of work done by nongovernmental organizations of men having sex with men (MSM) with the collaboration of Nepal government there is high prevalence of unprotected anal sex with a high incidence of sexual partner change. The purpose of this study was to explore knowledge about Human Immunodeficiency Virus (HIV) transmission, behavior and self-perception about risk of getting HIV among men having sex with men in Kathmandu Valley.

Methods: This is cross-sectional explorative study. Study was carried out between July 2010 and December 2010 in 97 men having sex with men in Kathmandu Valley using snow balling sampling technique. The verbal consent was taken and the respondents were interviewed using structured questionnaire.

Results: Although overall knowledge regarding HIV/AIDS and Sexual transmitted Infections (STI) is high some misconception about way of transmission is present. Majority of respondents still practiced unsafe sexual behaviors, which included multiple sex partners, irregular use of condom, frequent and regular anal sex, sex in exchange of money. More than half of them considered that they had little risk of getting HIV/AIDS.
\end{abstract}

Conclusion: Sexual behavior of men having sex with men needs to be further addressed in order to promote safer and responsible sexual behavior.

Keywords: HIV/AIDS, knowledge, men having sex with men

\section{Introduction}

The HIV/AIDS epidemic in Nepal has been termed as a "concentrated epidemic" with high prevalence among specific sub population. These high risk sub-populations are men having sex with men, sex workers, intravenous drug users and migrant workers. While estimated prevalence of HIV/AIDS among general population in Nepal is $0.5 \%{ }^{1}$, HIV prevalence among men who have sex with men has increased from $3.4 \%$ in 2007 to $3.8 \%$ in $2009^{2}{ }^{\prime 3}$.

Important characteristics of HIV epidemics in the Asian region and particularly in Nepal are: unprotected paid sex, the sharing of contaminated needles and syringes and unprotected sex between men. The term 'men having sex with men' (MSM) designed to encompass all men who have sex with men, regardless of their sexual identity ${ }^{4}$.

Total estimated population of men having sex with men and Transgender in Nepal are 134,905 ${ }^{5}$.

MSMs are considered to be at significant risk of getting HIV due to high prevalence of unprotected anal sex, multiple sexual partner, lack of knowledge about HIV/ AIDS transmission and prevention ${ }^{6-10}$. In spite on this many of MSMs consider themselves at low risk of getting HIV ${ }^{11}$. 
Most of men having sex with men are married and can transmit HIV/AIDS to their spouses ${ }^{12}$. Many are involved in sex work, often as a result of discriminatory social attitudes towards them in society, which makes it difficult for them to find alternative employment ${ }^{12}{ }^{13}$. Rather it appears that sex between men may be a significant route of HIV transmission within a generalized HIV epidemic in $\mathrm{Nepal}^{6}$.

In present study MSMs were categorized according to their self identification by sexual orientation on Meti, Ta and gays. Meti are biologically males who see themselves as feminine. They generally identify themselves as distinct from the gay/bisexual community in Nepal. They have sexual relationship with Ta. Ta are masculine men in Nepal who have sex (usually in the penetrative role) with Meti. Gay: a person who is physically and emotionally attracted to someone of the same sex. Depending upon the sexual behavior, MSMs are categorized as Penetrators (perform the penetrative role), Receivers (have receptive role on sexual act i.e. they are penetrated) and Dohori (both penetrators and receivers depending upon the situation) ${ }^{14-16}$.

Men having sex with men constitute one of the groups at highest risk of HIV transmission due to their high levels of risky behaviors and limited prevention coverage ${ }^{17}$. This research is aimed to assess behavior, awareness about way transmission and prevention of HIV, self-perception about risk of getting HIV among MSM. Results of the study will be helpful in developing rational plans and strategies for effective interventions to prevent HIV transmission.

\section{Methods}

This was a cross sectional, descriptive exploratory study conducted during July 2010 to December 2010 in Kathmandu Valley among men having sex with men. Because MSM is hidden population in Nepali society, it was difficult to construct sample frame for this research. Hence non - probability, snow balling sample was used.

For the sample estimation we considered $\mathrm{p}=16.8 \%$ which was prevalence of consistent condom use among MSMs over past 12 months ${ }^{3}$, with marginal error $=8 \%$ and confidence interval $95 \%$. Since sexual behavior of MSMs is a sensitive issue, $10 \%$ non respond rate was taken and altogether 97 MSMs were included in the study. Men having sex with men under 16 years old and mentally disable MSMs were excluded. A quantitative research approach was adopted for the study. Structured questionnaires were used to collect behavioral data relating to sexual behavior, sex partners, and use of condoms among MSMs as well as knowledge about way of transmission of HIV and demographic and social characteristics.
Pretesting of the tools was done in $10 \%$ of the sample size. Data was entered and edited in Microsoft Excel 2007. Coding of the variables was done. Data transferred to SPSS 17.0 and analyzed. Descriptive statistics included percentage for categorical data and mean (Standard deviation) for age of the respondents were computed.

\section{Ethical consideration}

The respondents were explained the objectives and purpose of the study. The informed verbal consent was taken. Privacy and confidentiality of information was strictly maintained and voluntary participation and anonymity of the research participants was ensured. Research proposal was reviewed and approved by the Thesis Committee of Department of Community Medicine and Family Health of Maharajgunj Medical Campus, Tribhuvan University.

\section{Results}

\section{Respondent's profile}

The mean age was found to be 28.1 years ( $\mathrm{SD} \pm 7.4$ ). One third $(33 \%)$ of the respondents had high secondary education followed by $30.9 \%$ with secondary education and $24.5 \%$ with primary education. Remaining $8.5 \%$ were illiterate and $3.2 \%$ had bachelor. Among the respondents $41.5 \%$ performed receptive role in the sexual relationship with male sex partners, remaining $39.4 \%$ were Dohori and $19.1 \%$ performed penetrative role. Majority $(64.9 \%)$ of the respondents self identified themselves by sexual orientation as Meti followed by $24.5 \%$ gay and $10.6 \%$ Ta. Nearly $31 \%$ of respondents reported to be married.

Table 1: Marital status according sexual behavior and sexual orientation

\begin{tabular}{cccc} 
Characteristics & \multicolumn{2}{c}{ Marital status } & Total \\
& $\begin{array}{c}\text { Married } \\
\text { n }(\%)\end{array}$ & Not married & $\mathrm{n}$ \\
& & & \\
Sexual behavior & & & \\
Penetrative & $4(22.2)$ & $14(77.8)$ & 18 \\
Receptive & $12(30.8)$ & $27(69.2)$ & 39 \\
Dohori & $13(35.1)$ & $24(64.9)$ & 37 \\
Sexual orientation & & & \\
Meti & $20(32.8)$ & $41(67.2)$ & 61 \\
Gay & $7(30.4)$ & $16(69.6)$ & 23 \\
Ta & $2(20.0)$ & $8(80.0)$ & 10 \\
Total & $29(30.9)$ & $65(69.1)$ & 94
\end{tabular}


Regarding the occupation, $19.1 \%$ were civil servant, followed by student $17 \%$, business/trade $14.9 \%$ and laborer $13.8 \%$. Unemployed occupied $11.7 \%$. Nearly $11 \%$ of respondent designated themselves as male sex workers (MSW). But during the study it was evaluated that other respondents also have had sex for money, but they did not identify themselves as male sex workers.

\section{Sexual behavior of the respondents}

More than half (52.5\%) of Meti, $40 \%$ of Ta and $34.8 \%$ of gays reported presence of regular sexual partner. More than one third (35.1\%) had male and nearly $12 \%$ had female as current sexual partner. All female were wives. The majority of respondents $(83 \%)$ had practiced anal sex in the last sex followed by $67 \%$ percent oral sex and $3.2 \%$ vaginal sex. More than half of the respondents had sexual relationship in exchange of money. Majority of them (70\%) were Meti.

Table 2: Sex for money according sexual behavior and sexual orientation

\begin{tabular}{llcc} 
Characteristics & \multicolumn{2}{c}{ Sex for money } & Total \\
& Had & Did not have & $\mathrm{n}$ \\
& $\mathrm{n}(\%)$ & $\mathrm{n}(\%)$ & \\
\hline Sexual behavior & & & \\
Penetrative & $5(27.8)$ & $13(72.2)$ & 18 \\
Receptive & $31(79.5)$ & $8(20.5)$ & 39 \\
Dohori & $18(48.6)$ & $19(53.4)$ & 37 \\
Sexual orientation & & & \\
Meti & $42(68.9)$ & $19(31.1)$ & 61 \\
Gay & $9(39.1)$ & $14(60.9)$ & 23 \\
Ta & $3(30)$ & $7(70)$ & 10 \\
Total & $54(57.4)$ & $40(42.6)$ & 94
\end{tabular}

MSMs had high number of sexual partners in the past 3 months: nearly $34 \%$ of the respondents had 2-10 male sex partners, $18.1 \%$ and $16.0 \%$ had high number of male sex partners from 21-50 and 11-20 partners respectively. Only $9.6 \%$ of the respondents had single partner in the past 3 months. Quarter (25\%) of the respondents reported about sex with female in the last 3 months.

\section{Condom use}

Majority (76.6\%) of the respondents always used condom. Most of the MSMs (97\%) had no difficulties to obtain condom every time they need it. Usual source of condom for MSMs were NGOs drop in centers (95\%). Nearly $10 \%$ of the respondents who did not use condom believe that they were not at risk of getting disease. Majority (78.7\%) of the respondents always use lubricant with condom during anal sex in the last 30 days. Remaining $12.9 \%$ said that lubricant cost too much, $4.2 \%$ used other cream, $3.1 \%$ shy to buy lubricant and $1.1 \%$ did not know where to obtain lubricant.

\section{Knowledge about HIV/STD}

Only 46 respondents (46.9\%) from 94 gave all correct answer about symptoms of STI. Remaining 48 respondents $(51.06 \%)$ have mentioned at least one misconception about symptoms of STI. All respondents had heard about HIV/ AIDS and majority $(88.3 \%)$ knew somebody who was infected by HIV. Most (91.5\%) of the respondents reported that healthy looking person could transmit HIV. Majority $(71.3 \%)$ of the respondents gave all correct answer about way of transmission of HIV/AIDS. Remaining 28.7\% had mentioned at least one misconception about way of transmission of HIV/AIDS.

\section{Self perception about risk of getting HIV/AIDS by respondents}

Many of the respondents did not identify themselves as at risk population.

Table 3: Sexual orientation and self perception about risk of getting HIV by respondents

\begin{tabular}{|c|c|c|c|c|c|}
\hline \multirow[t]{2}{*}{$\begin{array}{l}\text { Sexual } \\
\text { orientation }\end{array}$} & \multicolumn{5}{|c|}{$\begin{array}{l}\text { Self perception about } \\
\text { risk of getting disease }\end{array}$} \\
\hline & High risk & Some risl & Little risk & Did not 1 & \\
\hline & $\mathrm{n}(\%)$ & n (\%) & $\mathrm{n}(\%)$ & $\mathrm{n}(\%)$ & \\
\hline Meti & $18(29.5)$ & $21(34.4)$ & $20(32.8)$ & $2(3.3)$ & 61 \\
\hline Gay & $2(8.7)$ & $(52.2)$ & $8(34.8)$ & $1(4.3)$ & 23 \\
\hline $\mathrm{Ta}$ & 0 & $4(40)$ & $6(60)$ & 0 & 10 \\
\hline Total & $20(21.3)$ & $37(39.4)$ & $34(36.2)$ & $3(3.2$ & 94 \\
\hline
\end{tabular}

Among the respondents considered themselves at high risk of getting HIV/AIDS nearly $40 \%$ identified risk due to multiple sex partners, $28.7 \%$ of the MSMs have frequent and regular anal sex and 19\% didn't use condom regularly. Remaining $13.8 \%$ mentioned about high risk job and $5.3 \%$ needle sharing. Among those respondents who percept themselves at low risk of getting HIV more than half $(53.2 \%)$ always use condom, $26.6 \%$ reported than they never share injections, $20.2 \%$ had only one sex partner and $16 \%$ thought that their partners were clean and healthy. 


\section{Health seeking behavior}

Majority (69.1\%) of the respondents did not have any symptoms of STI at the time of study. Nearly $15 \%$ of the respondents had urinal discharge, genital, anal and oral ulcer had $13.8 \%$ each and $10.6 \%$ had anal discharge. Majority $(23.4 \%)$ sought treatment from BDS clinics. Remaining $2.1 \%$ sought treatment from hospital, from chemist, private clinics and self treatment sought $1.1 \%$ each and $2.1 \%$ of the respondents did not have any treatment.

Half of the respondents (50\%) preferred governmental hospitals to go with any health problems, 34\% sought help from MSMs NGO clinics, $31.9 \%$ went to private hospitals and remaining $1.1 \%$ did not go anywhere. Nearly $26 \%$ of the respondents reported about discrimination in health facilities by health personnel.

\section{HIV test among study population}

All the respondents had knowledge about the place where to go for confidential HIV test. Majority $(91.5 \%)$ of them had HIV test in the past. Nearly $80 \%$ had test within last year, $11.7 \%$ more than 1 year ago and $8.5 \%$ did not do HIV test. Most of the respondents (76.6\%) had HIV test voluntary and remaining $14.9 \%$ were asked to do HIV test.

\section{Discussion}

During this study it was found that respondents still practiced unsafe sexual behaviors, which included multiple sex partners, irregular use of condom, frequent and regular anal sex, sex in exchange of money. Most of the MSMs $(83 \%)$ had anal sex during last time, followed by $67 \%$ who had oral sex. Out of total respondents of present study more than half (57.4\%) reported about sexual relationship in exchange of money. Majority of them were Meti (70\%). It has increased visibly if compare with IBBS survey in 2009 where overall, $35.5 \%$ of MSMs reported ever having sex with a male partner in exchange for money ${ }^{4}$ and with the study in Ho Chi Minh City, Vietnam where 31\% of respondents had earned money through $\operatorname{sex}^{8}$.

Also the respondents were involved in sexual relationship with females including wives. Nearly $31 \%$ of the respondents were married compared with IBBS 2009 where $25 \%$ of MSM were currently married ${ }^{4}$. Some of the respondents of present study got married when they were young and were not aware about their sexual orientation. Remaining respondents got married with intention to hide their sexual orientation from society and some of them were forced to get married. Among respondents who reported about sex for money $6.4 \%$ had sex with female sex partner.

In present study $46.8 \%$ of the respondents had current sexual partner. Among them $35.1 \%$ had male and $11.5 \%$ had wife as current sex partner. Number of the MSM who had regular sexual partner had increased if compare with IBBS 2009 where $77.5 \%$ of respondents did not have a regular sex partner at the time of the survey. Among those who lived with a regular partner, $55.6 \%$ of the MSM lived with a woman ${ }^{4}$. In contrast with the study in Ho Chi Minh City, Vietnam conducted in 2003, where most of the respondent $(81 \%)$ reported sex with non regular male partners ${ }^{8}$.

Still many of the respondents have multiple sexual partners. Tendency to have high number of sexual partners were seen among Meti. Among respondents who had more than 100 sexual partners in the last 3 months were Meti.

During study it was found that nearly $88 \%$ of the respondents used condom during last sex. The situation is improving if compare with previous studies in Ho Chi Minh City, Vietnam where only $32 \%$ used condoms during their last intercourse ${ }^{8}$ and compare with the IBBS survey of 2009 where $71.3 \%$ of MSMs had used condom in their last sexual contact ${ }^{4}$. But still it is not enough considered free access to condom in Kathmandu Valley through drop in centers of MSMs NGO Blue Diamond Society (BDS). According IBBS survey only about a third of the MSM (32.3\%) were carrying condoms with them at the time of the interview ${ }^{4}$ compare with $95.7 \%$ of the respondents in present study.

It was found decrease in lubricant using practice - about $79 \%$ of respondents used lubricant with condom during last anal sex compared with $96.5 \%$ of MSMs in IBBS study ${ }^{4}$. But during group discussion in the study "HIV- related risk vulnerability and social networks in five study sites in Nepal" conducted in Nepal in 2008 in Biratnagar, Birganj, Bhairawa, Butwal and Nepalganj were estimated that possibly only $40 \%$ of the MSM used lubricants ${ }^{15}$. So it was seen that MSMs who lived in Kathmandu Valley were more aware about lubricants than MSMs from all Nepal.

Findings of the study show that majority of the respondents have knowledge about way of transmission and prevention of HIV/AIDS and symptoms of STI, but still there are misconceptions. Only 46 respondents (46.9\%) from 94 gave all correct answer about symptoms of STI. Most of the respondents $(71.3 \%)$ gave all correct answer about way of transmission of HIV/AIDS compare to IBBS study where $83.3 \%$ of MSM were aware of all major modes of transmission HIV/AIDS ${ }^{4}$. In spite of high coverage of MSMs living in Kathmandu Valley by HIV and STI programs there were found misconceptions about way of transmission of HIV and knowledge of symptoms of STI among respondents. 
In spite of common unsafe sexual behavior among MSMs only $21.3 \%$ of the respondents considered that they had high risk of getting HIV/AIDS. It was seen that Meti perceived them at higher risk if compare with others groups because they had the highest number of sex partners and high percent of them had sex for money. During study "HIV- related risk vulnerability and social networks in five study sites in Nepal" conducted in 2008 in most sites respondents did not consider themselves at risk of HIV infection. In Kathmandu only $2 \%$ of 400 surveyed MSM perceived their risk of HIV infection as high as opposed to almost 70 who believed it was insignificant ${ }^{15}$. In the study in Beijing, China an overwhelming majority (85\%) of respondents believed that they were at either no risk at all or low risk for HIV ${ }^{12}$. Compare with previous studies more respondents perceived their risk of getting HIV as high. It can be explained by improving knowledge of way of transmission of HIV and increasing awareness about practice of unsafe sexual behavior.

All respondents had knowledge about the place where to go for confidential HIV test in Kathmandu and majority $(91.5 \%)$ of them had HIV test in the past. However, in the IBBS survey it was found that $83 \%$ of the MSMs knew about the existence of a confidential HIV testing facility in their community. There were only $42 \%$ of MSMs who received an HIV test in the last 12 months and who know their results ${ }^{4}$. Compare to IBBS survey the percentage of the MSMs who had HIV test in present study increased visibly that shows positive impact of HIV related programs among MSMs which were implemented by MSMs NGO.

\section{Conclusion}

Though knowledge regarding HIV/AIDS/STI was good, majority of MSMs are involved in unsafe sexual practices and more than half respondents considered themselves at some or little risk of getting HIV/AIDS. Due to lack of understanding, ignorance of the consequences and existed stigma and discrimination in Nepal society, MSMs are involved in sex work and risky sexual behavior. Results of this study suggest that MSM's sexual and health issues need to be further addressed in order to promote safer and responsible sexual behavior.

\section{References}

1. Department of Health Services (DoHS). Annual Report, 2064/2065 (2007/2008). Kathmandu: DoHS; 2009.

2. FHI/New ERA/SACTS. Integrated Bio- behavioral survey among men who have sex with men in the Kathmandu Valley. Kathmandu; 2007.
3. FHI/New ERA/SACTS. Integrated Bio- behavioral survey among men who have sex with men in the Kathmandu Valley. Kathmandu; 2009.

4. Report of the commission on AIDS in Asia, redefining AIDS in Asia. New Delhi: Oxford University ress; 2008.

5. UNDP. Blue Diamond Society Annual Report 2009. Kathmandu: An HIV/AIDS and Human Rights Program; 2009.

6. Family Health International. Rapid ethnography of male to male sexuality and sexual health. Kathmandu:FHI; 2001 [cited on April 2010]. Available from http:// www.fhi. org/nr/rdonl res/6uzszv3csgem2ra2cty6iu7id221650o3wfsua3ifpj z2xnsup k4ruo/fhimsmrpt23.pdf

7. UNAIDS. HIV and sex between men. Geneva: Joint United Nations Program on HIV/AIDS; 2006. [cited on April 2010]. Available from http://data.unaids. org/ pub/ BriefingNote/2006/20060801_policy_brief_ msm_en.pdf

8. Donn C, Cao NH. HIV knowledge and risk factors among men who have sex with men in Ho Chi Minh City, Vietnam. JAIDS Journal of Acquired Immune Deficiency Syndromes 2003; 32(1): 80-85.

9. Lau JTF, Kim JH, Lau M. HIV related behaviors and attitudes among Chinese men who have sex with men in Hong Kong: a population based study. Sex Transm Inf 2004; 80:459-465.

10. Population Services International. Knowledge, attitudes and practices related to HIV/AIDS and STIs among transgender and their partners in the Laos: results of baseline survey. PSI; 2004.

11. UNAIDS. HIV and men who have sex with men in Asia and the Pacific. Geneva: WHO; 2006 [cited on April 2010]. Available from http://data.unaids.org/ Publications/ IRC-pub07/jc901-msm- asiapacific_ en.pdf

12. Choi K-H, Gibson DR, Han L, Guo Y. High levels of unprotected sex with men and women among men who have sex with men: a potential bridge of HIV transmission in Beijing, China. AIDS Education and Prevention 2004; 16(1): 19-30.

13. Cáceres CF, Pecheny M, Frasca T, Rios RR, Pocahy F. Review of legal frameworks and the situation of human rights related to sexual diversity in low and middle income countries. UNAIDS; 2009. 
14. Treat Asia, The Foundation for AIDS Research. Ensuring universal access to comprehensive HIV services for MSM in Asia and the Pacific. amfAR; 2009.

15. UNAIDS Nepal. HIV-related risks, vulnerability and social networks in five study sites in Nepal.

Kathmandu: Joint United Nations Program on HIV/ AIDS; 2009.

16. Ghimire S, Onta S, Shrestha N. Health care seeking practices of male having sex with males (MSMs) in Kathmandu Valley. Journal of Nepal Public Health Association 2006 June; 3(1):25-28.

17. Beyrer C. Hidden yet happening: the epidemics of sexually transmitted infections and HIV among men who have sex with men in developing countries. Sex Transm Infect 2008; 84: 410-412. 